\title{
Small Fast Spectrum Reactor Designs Suitable for Direct Nuclear Thermal Propulsion
}

\author{
Bruce G. Schnitzler ${ }^{1}$ \\ Idaho National Laboratory, Idaho Falls, Idaho 83415 \\ and \\ Stanley K. Borowski ${ }^{2}$ \\ NASA Glenn Research Center, Cleveland, Ohio 44135
}

\begin{abstract}
Advancement of U.S. scientific, security, and economic interests through a robust space exploration program requires high performance propulsion systems to support a variety of robotic and crewed missions beyond low Earth orbit. Past studies, in particular those in support of the Space Exploration Initiative (SEI), have shown nuclear thermal propulsion systems provide superior performance for high mass high propulsive delta-V missions. The recent NASA Design Reference Architecture (DRA) 5.0 Study re-examined mission, payload, and transportation system requirements for a human Mars landing mission in the post-2030 timeframe. Nuclear thermal propulsion was again identified as the preferred in-space transportation system. A common nuclear thermal propulsion stage with three $25,000-\mathbf{l b}_{\mathrm{f}}$ thrust engines was used for all primary mission maneuvers. Moderately lower thrust engines may also have important roles. In particular, lower thrust engine designs demonstrating the critical technologies that are directly extensible to other thrust levels are attractive from a ground testing perspective. An extensive nuclear thermal rocket technology development effort was conducted from 1955-1973 under the Rover/NERVA Program. Both graphite and refractory metal alloy fuel types were pursued. Reactors and engines employing graphite based fuels were designed, built and ground tested. A number of fast spectrum reactor and engine designs employing refractory metal alloy fuel types were proposed and designed, but none were built. The Small Nuclear Rocket Engine (SNRE) was the last engine design studied by the Los Alamos National Laboratory during the program. At the time, this engine was a state-of-the-art graphite based fuel design incorporating lessons learned from the very successful technology development program. The SNRE was a nominal $16,000-1 b_{f}$ thrust engine originally intended for unmanned applications with relatively short engine operations and the engine and stage design were constrained to fit within the payload volume of the then planned space shuttle. The SNRE core design utilized hexagonal fuel elements and hexagonal structural support elements. The total number of elements can be varied to achieve engine designs of higher or lower thrust levels. Some variation in the ratio of fuel elements to structural elements is also possible. Options for SNRE-based engine designs in the $25,000-\mathrm{lb}_{\mathrm{f}}$ thrust range were described in a recent (2010) Joint Propulsion Conference paper. The reported designs met or exceeded the performance characteristics baselined in the DRA 5.0 Study. Lower thrust SNRE-based designs were also described in a recent (2011) Joint Propulsion Conference paper. Recent activities have included parallel evaluation and design efforts on fast spectrum engines employing refractory metal alloy fuels. These efforts include evaluation of both heritage designs from the Argonne National Laboratory (ANL) and General Electric Company GE-710 Programs as well as more recent designs. Results are presented for a number of not-yet optimized fast spectrum engine options.
\end{abstract}

\footnotetext{
${ }^{1}$ Space Nuclear Systems Division, 2525 N. Fremont Avenue, Idaho Falls, ID 83415-3870, AIAA Senior Member.

${ }^{2}$ DDS Branch Chief \& Lead Engineer, NTP Systems, 21000 Brookpark Road, MS:86-4, AIAA Associate Fellow.

1

American Institute of Aeronautics and Astronautics
} 


\section{Nomenclature}

$\begin{array}{ll}\text { ANL } & =\text { Argonne National Laboratory, Argonne, Illinois } \\ \text { cermet } & =\text { ceramic-metallic, generally fuel containing uranium in a refractory metal alloy matrix } \\ \text { DRA } & =\text { Design Reference Architecture } \\ \text { ENDF/B } & =\text { (United States) Evaluated Nuclear Data File } \\ \text { GE } & =\text { General Electric } \\ \text { Isp } & =\text { specific impulse (seconds) } \\ \text { k-eff } & =\text { effective multiplication factor } \\ \mathrm{K} & =\text { temperature (Kelvin) } \\ \mathrm{lb}_{\mathrm{f}} & =\text { pounds thrust } \\ \mathrm{lb}_{\mathrm{m}} & =\text { pounds mass } \\ \text { MCNP } & =\text { ponte Carlo N-Particle transport code } \\ \text { MPa } & =\text { thermal power (megawatts) } \\ \text { MWth } & =\text { United States) National Aeronautics and Space Administration } \\ \text { NASA } & =\text { Nuclear Engine System Simulation code } \\ \text { NESS } & =\text { Nuclear Engine for Rocket Vehicle Applications } \\ \text { NERVA } & =\text { Nuclear Thermal Propulsion } \\ \text { NTP } & =\text { Nuclear Thermal Rocket } \\ \text { NTR } & =\text { Strategic Exploration Initiative } \\ \text { SEI } & \text { Small Nuclear Rocket Engine } \\ \text { SNRE } & \end{array}$

\section{Introduction}

dvancement of U.S. scientific, security, and economic interests requires high performance propulsion systems to support missions beyond low Earth orbit. A robust space exploration program will include robotic outer planet and crewed missions to a variety of destinations including the moon, near Earth objects, and eventually Mars. Past studies, in particular those in support of the Space Exploration Initiative (SEI), have shown nuclear thermal propulsion systems provide superior performance for high mass high propulsive delta-V missions. In NASA's recent Mars Design Reference Architecture (DRA) $5.0 \mathrm{study}^{1}$, nuclear thermal propulsion (NTP) was again selected over chemical propulsion as the preferred in-space transportation system option for the human exploration of Mars because of its high thrust and high specific impulse ( $~ 900 \mathrm{~s})$ capability, increased tolerance to payload mass growth and architecture changes, and lower total initial mass in low Earth orbit. The recently announced national space policy $^{2}$ supports the development and use of space nuclear power systems where such systems safely enable or significantly enhance space exploration or operational capabilities.

In the DRA 5.0 study, a common nuclear thermal propulsion stage with three $111.2 \mathrm{kN}\left(25,000 \mathrm{lb}_{\mathrm{f}}\right)$ engines was used for all primary mission maneuvers. Moderately lower thrust engines may also have important roles. Robotic science missions could benefit directly from smaller nuclear engines, even when NTP is not considered enabling for the particular mission or class of missions. Smaller nuclear engines are also more attractive for an in-space nuclear propulsion technology demonstrator prior to larger scale use for cargo and crewed exploration missions. The lower thrust engine designs could then be used to demonstrate critical technologies that are directly extensible to higher thrust levels.

An extensive nuclear thermal rocket technology development effort was conducted under the Rover/NERVA ${ }^{3}$, GE-710 ${ }^{4}$ and $\mathrm{ANL}^{5}$ nuclear rocket programs (1955-1973). Both graphite and refractory metal alloy fuel types were pursued. ${ }^{6}$ The primary and significantly larger Rover/NERVA program focused on graphite type fuels. Research, development, and testing of high temperature graphite fuels was conducted. Reactors and engines employing these fuels were designed, built, and ground tested. The Small Nuclear Rocket Engine (SNRE) ${ }^{7,8}$ was the last engine design studied by the Los Alamos National Laboratory during the program. At the time, this engine was a state-ofthe-art graphite based fuel design incorporating lessons learned from the very successful technology development program. The SNRE was a nominal $16,000-1 b_{f}$ thrust engine originally intended for unmanned applications with relatively short engine operations and the engine and stage design were constrained to fit within the payload volume of the then planned space shuttle. The SNRE core design utilized hexagonal fuel elements and hexagonal structural support elements. The total number of elements can be varied to achieve engine designs of higher or lower thrust levels. Some variation in the ratio of fuel elements to structural elements is also possible. Recent papers have described options for SNRE-based engine designs in both the $25,000-1 b_{f}$ thrust range ${ }^{9}$ and the lower thrust 
technology demonstrator thrust range ${ }^{10}$. Core components in the higher thrust designs can be identical to those employed in the lower thrust designs. The higher thrust designs met or exceeded the performance characteristics baselined in the DRA $5.0 \mathrm{Study}^{1}$.

The GE- $710^{4}$ and $\mathrm{ANL}^{5}$ programs focused on an alternative ceramic-metallic "cermet" fuel type consisting of $\mathrm{UO}_{2}$ (or UN) fuel embedded in a refractory metal matrix such as tungsten. The General Electric program examined closed loop concepts for space or terrestrial applications as well as open loop systems for direct nuclear thermal propulsion. Although a number of fast spectrum reactor and engine designs suitable for direct nuclear thermal propulsion were proposed and designed, none were built. Recent activities have included parallel evaluation and design efforts on fast spectrum engines employing refractory metal alloy fuels. These efforts include evaluation of both heritage designs from the Argonne National Laboratory (ANL) ${ }^{5}$ and General Electric Company GE-710 ${ }^{4}$ Programs as well as more recent designs. Results are presented for a number of not-yet optimized fast spectrum engine options.

\section{Engine Design and Analysis Methods}

Engine design and analysis requires consideration and evaluation of neutronic performance, the combined thermal-fluid-structural performance of reactor interior components, and engine system level performance. An effective design and analysis sequence is to first establish a preliminary core configuration that meets the fundamental neutronic performance requirements of criticality and adequate control swing. Results from neutronic analyses of the reactor core can then be utilized to provide neutron and gamma energy deposition rates as input to integrated thermal-fluid-structural analyses of the core interior components. Once acceptable neutronic and thermal performance is achieved, overall engine system performance can be evaluated. The above sequence is typically an iterative process.

Preliminary core configurations typically employ fuel elements with fixed fuel composition and fissile material enrichment. Uniform fuel loading usually results in undesirable radial power and temperature profiles in the engine. Engine performance can be improved by some combination of propellant flow control at the fuel element level and by varying the fuel composition. Enrichment zoning at the fuel element level with lower enrichments in the higher power elements at the core center and on the core periphery is particularly effective. Power flattening by enrichment zoning typically results in more uniform propellant exit temperatures and improved engine performance at the cost of some reactivity loss. Compensation for the reactivity loss is possible by several methods. Again, an iterative process is usually needed.

Another important step in the design and analysis sequence is to evaluate fissile depletion and fission product buildup during engine operation. Engine operating times are usually short with low reactivity loss. Reactivity losses due to depletion can be accommodated by control drum rotation, but drum rotation also results in core power distribution changes that can lower engine performance.

Historically, a variety of analytic methods have been utilized in the design and performance evaluations of nuclear thermal propulsion systems. The most important have been Monte Carlo, one-dimensional and multidimensional discrete ordinates transport, and point-kernel methods. The selection of both analytic methods and the level of modeling detail to be employed are influenced by several factors including model development time, available computational capacity, and the intended application of the results. Lower fidelity solutions may often suffice for some scoping studies such as preliminary engine sizing. At the other end of the spectrum is the reactor equivalent of modern aircraft design where a vehicle may be flown computationally as an integral part of the design process.

All transport evaluations reported here were performed using the MCNP Monte Carlo transport code. ${ }^{11}$ Cross section data employed in the MCNP transport calculations are primarily from the Evaluated Nuclear Data File ${ }^{12,13}$ (ENDF/B) Versions V and VI. The ENDF/B cross section evaluations for some materials of interest, in particular the zirconium and hafnium isotopes, do not include photon yield data. The ENDF/B evaluations were employed for estimating core reactivity and alternate Lawrence Livermore evaluations ${ }^{14}$ for some materials substituted for energy deposition evaluations.

There is current interest in both nominal $25,000-\mathrm{lb}_{\mathrm{f}}$ class designs and in lower thrust designs demonstrating technologies that are directly extensible to the higher thrust level. As with the thermal neutron spectrum engines, core reactivity considerations will be more constraining in the lower thrust systems. Lower thrust systems may be characterized as criticality limited. The approach taken here is to first focus on selected lower thrust designs using a variety of fuel types described in the next section. Higher thrust versions of any or all of the lower thrust designs can then be evaluated. In all cases, the growth versions utilize the same hexagonal fuel element type as the lower thrust counterpart. 


\section{Fast Spectrum Systems}

The GE- $710^{4}$ and $\mathrm{ANL}^{5}$ nuclear rocket programs focused on refractory metal alloy fuels for both power and propulsion concepts. Both programs had been established as backups to the primary Rover/NERVA ${ }^{3}$ using graphite based fuels. The choice of refractory metal alloy fuels as the secondary fuel type had been based on a combination of the greater experience base, lower thermal neutron absorption cross-section, and ease of fabrication for the graphite fuels.

The 710 Program had been initiated in 1962 with the direction to conduct reactor tests demonstrating performance for both closed loop systems using neon as the coolant and open loop systems using hydrogen as the coolant and propellant. Program direction was changed in 1963, 1965, and 1966 prior to termination in 1968. The open loop direct propulsion test was dropped with the 1963 direction.

Two reference engine designs were developed during the ANL program. The primary was a $2000 \mathrm{MWth}$ engine yielding $489.7 \mathrm{kN}\left(110,100 \mathrm{lb}_{\mathrm{f}}\right)$ thrust with a specific impulse of 832 seconds. The engine operated on a topping cycle. The second reference design developed $46.8 \mathrm{kN}\left(10,530 \mathrm{lb}_{\mathrm{f}}\right)$ thrust with a specific impulse of 821 seconds. This engine operated on a hot bleed cycle. A nozzle expansion ratio of 50:1 was used for both designs.

Fast spectrum reactor systems have been revisited since the 1973 program terminations. In particular, Argonne National Laboratory and General Electric collaborated on a study ${ }^{15}$ funded by the Air Force Astronautics Laboratory to evaluate fast spectrum reactors for direct nuclear thermal propulsion. Pratt \& Whitney has proposed the $\mathrm{XNR} 2000^{16}$ as a near term fast spectrum reactor concept for direct nuclear thermal propulsion as well as the ESCORT $^{17}$ bimodal and TRITON ${ }^{18}$ trimodal concepts.

Advertised advantages of fast spectrum systems include the potential for better fission product retention, long operating life with multiple restarts and temperature cycling, and an intrinsic "neutronic spectral shift" safety feature that helps maintain reactor subcriticality in the event of a water immersion accident. Fast spectrum reactors also tend to be much more compact than thermal spectrum systems, although that does not automatically translate to lower mass systems with higher thrust-to-weight. The inherently higher fissile mass of a fast spectrum system is an important disadvantage.

\section{Cermet Nuclear Fuels}

\section{A. Fuel Compositions}

Haertling and Hanrahan ${ }^{19}$ have summarized refractory metal alloy fuels development for propulsion engines. Bhattacharyya ${ }^{6}$ has also summarized refractory metal alloy and other fuels suitable for nuclear thermal propulsion. The ceramic-metallic "cermet" fuels contain $\mathrm{UO}_{2}$ or $\mathrm{UN}$ in a refractory metal matrix. The UN fuels were primarily considered for applications with operating temperature lower than those desired for nuclear thermal propulsion. Refractory metals suitable for the very high temperatures desired are tungsten, molybdenum, tantalum, rhenium and their alloys. Spherical particles of $\mathrm{UO}_{2}$ are usually employed and the particles may be bare or coated. Tungsten is the coating of choice, especially for fuels using tungsten or tungsten alloys as the metal matrix. Particle size is an important variable and one or multiple sizes may be used. Oxygen stabilizers may be added to the fuel particle, to the metal matrix, or to both. The stabilizer of choice was $\mathrm{ThO}_{2}$ for the 710 Program and $\mathrm{Gd}_{2} \mathrm{O}_{3}$ for the ANL Program. Fuel loadings of up to $60 \% \mathrm{UO}_{2}$ (by volume) in the metal matrix were assumed for both GE-710 and ANL engine designs. The $\mathrm{W}-\mathrm{UO}_{2}$ cermet density or fraction of theoretical density is also an important variable.

\section{B. Clad Compositions}

Several materials have been evaluated for the cladding on the propellant channels and on the exterior surfaces of the hexagonal fuel elements. The 710 Program tested tantalum, the tantalum alloys Ta- $10 \mathrm{~W}$ and Ta- $8 \mathrm{~W}-2 \mathrm{Hf}$ (T-111), Mo-50Re, W-25Re-30Mo, and W-30Re-30Mo. The W-30Re-30Mo (by atom percent) alloy was the preferred clad for direct propulsion designs at the close of the program. The ANL designs used tungsten for the coolant channel clad and W-25Re for the exterior clad. The alloy is listed as both W-Re and W-25\% Re in multiple places in Reference 5. For the 2000 MWth engine the material is listed as W-25 wt\% Re and for the $200 \mathrm{MWth}$ engine it is listed as W-25Re by volume.

\section{Fuel Element Geometry}

Numerous hexagonal fuel element geometries have been considered for fast spectrum reactor power and propulsion concepts. Data for several elements proposed for propulsion engine designs are summarized in Table 1. In addition to the GE-710 and ANL heritage designs, data for other industry proposed concepts are listed. 
Table 1: Hexagonal fuel element geometry data in traditional engineering units for proposed propulsion engine concepts.

\begin{tabular}{|c|c|c|c|c|c|c|c|c|}
\hline $\begin{array}{l}\text { Element } \\
\text { Type }\end{array}$ & $\begin{array}{l}\text { Exterior } \\
\text { Width } \\
\text { (Inches) }\end{array}$ & $\begin{array}{c}\text { Exterior } \\
\text { Clad } \\
\text { (Inches) }\end{array}$ & $\begin{array}{c}\text { Number } \\
\text { of } \\
\text { Channels }\end{array}$ & $\begin{array}{l}\text { Channel } \\
\text { Pitch } \\
\text { (Inches) }\end{array}$ & $\begin{array}{l}\text { Matrix } \\
\text { Borehole } \\
\text { Diameter } \\
\text { (Inches) }\end{array}$ & $\begin{array}{c}\text { Borehole } \\
\text { Clad } \\
\text { (Inches) }\end{array}$ & $\begin{array}{c}\text { Hydrogen } \\
\text { Passage } \\
\text { Diameter } \\
\text { (Inches) }\end{array}$ & $\begin{array}{l}\text { Matrix } \\
\text { Web } \\
\text { (Inches) }\end{array}$ \\
\hline \multicolumn{9}{|c|}{ Heritage Cermet (ANL) } \\
\hline ANL-200 & 1.092 & 0.007 & 61 & 0.136 & 0.081 & 0.007 & 0.067 & 0.055 \\
\hline ANL-2000 & 1.930 & 0.030 & 331 & 0.102 & 0.081 & 0.007 & 0.067 & 0.021 \\
\hline \multicolumn{9}{|c|}{ Heritage Cermet (GE-710) } \\
\hline GE-710 & 0.9276 & 0.015 & 91 & 0.0938 & 0.052 & 0.008 & 0.036 & 0.042 \\
\hline \multicolumn{9}{|c|}{ Pratt \& Whitney Cermet } \\
\hline XNR-2000-A & 1.40 & 0.020 & 169 & 0.102 & 0.080 & 0.007 & 0.066 & 0.022 \\
\hline XNR-2000-B & 1.40 & 0.020 & 37 & 0.215 & 0.154 & 0.007 & 0.140 & 0.061 \\
\hline ESCORT & 1.70 & 0.040 & 48 & $\sim 0.225$ & 0.114 & 0.007 & 0.100 & $\sim 0.111$ \\
\hline \multicolumn{9}{|c|}{ Heritage NERVA Geometry } \\
\hline NE-X & 0.750 & 0.002 & 19 & 0.161 & 0.101 & 0.004 & 0.093 & 0.060 \\
\hline
\end{tabular}

Fuel element geometries are identified by the element type shown in the first column. In some cases the element type names also correspond to an engine design with the same name. This is the case for the ANL-200, ANL-2000, XNR-2000-A, and XNR-2000-B elements. The ESCORT element used in the ESCORT bimodal engine is identical to the element used in the trimodal TRITON engine. Recent consideration has been given to fabrication of a cermet fueled element similar in geometry to the NERVA hexagonal element. The heritage NERVA element geometry data for graphite fuel based thermal spectrum engine designs are included for comparison.

Although any particular element name may be derived from some specific engine design, that element design (element cross-section) can also be used in other engine configurations. In particular, the data shown in Table 1 are relevant to the element cross-section. The element lengths from the original engine designs are not shown and may be considered variable for the current application.

Several factors influence the design and appearance of the elements. Important geometry features are the element size, the number of coolant / propellant channels, the channel diameter, and the web thickness of the fuel matrix. The element exterior width listed in the second column is the exterior flat-to-flat dimension and includes the exterior clad thickness. Element widths for the heritage cermet designs range from 1.930 inches for the ANL-2000 to 0.9276 inch for the GE-710. The heritage NERVA graphite element is slightly smaller with an exterior flat-to-flat dimension of $0.750 \mathrm{inch}$. The nominal 0.002 -in exterior clad dimension will likely need to be revised for a cermet element. The value listed in the last column is the interior web thickness of the fuel matrix. Interior web thicknesses range from 0.021 inch for the ANL-2000 to $\sim 0.111$ inch for the ESCORT design. Variable channel spacing is employed in the ESCORT design and a nominal dimension is listed.

Thinner web thicknesses are generally associated with element designs for higher power density operation. Design power density for the ANL-2000 element with a 0.021 -in web thickness is $16.5 \mathrm{MW} /$ liter while the design power density for the GE-710 element with a 0.042 -in web is $13.5 \mathrm{MW} /$ liter.

Element cross-sections are shown in Figure 1 for six of the element types listed in Table 1. All cross-sections are plotted at the same scale. 


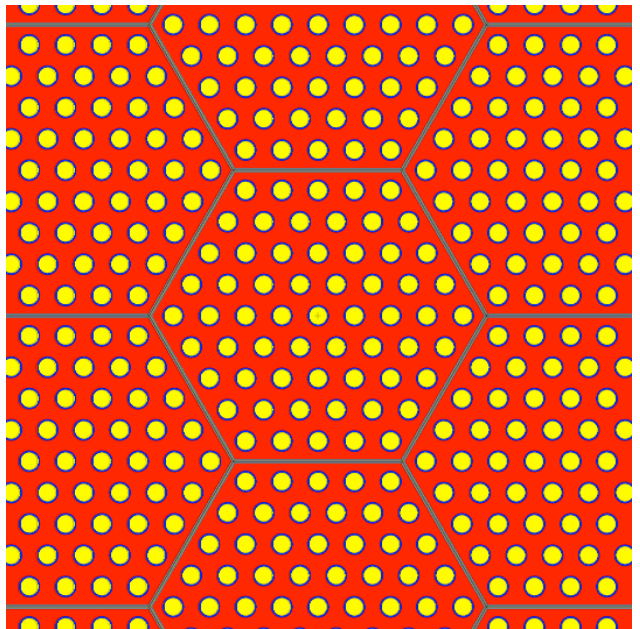

a) ANL-200 element cross-section.

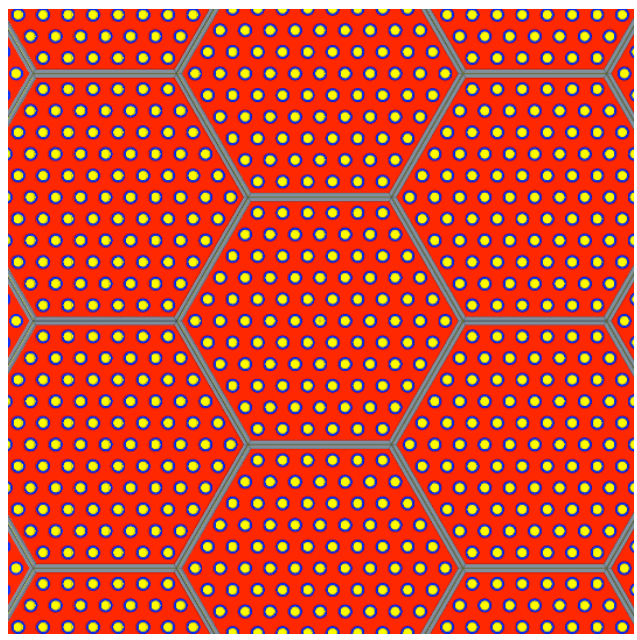

c) GE-710 element cross-section.

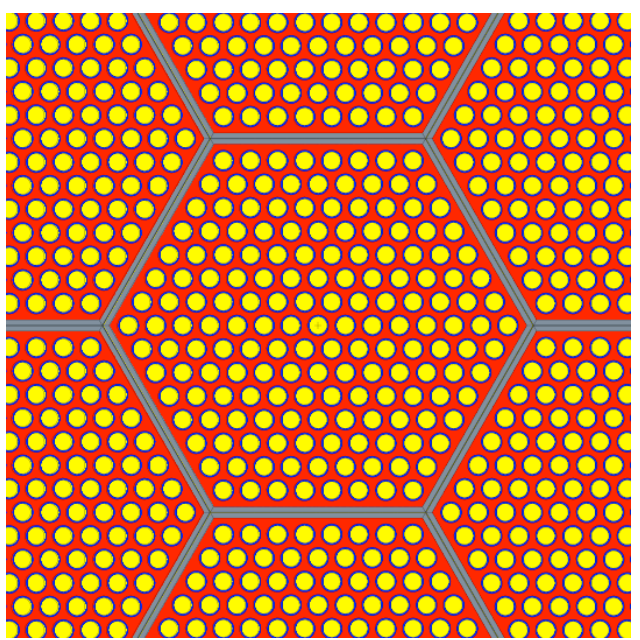

e) XNR-2000-A element cross-section.

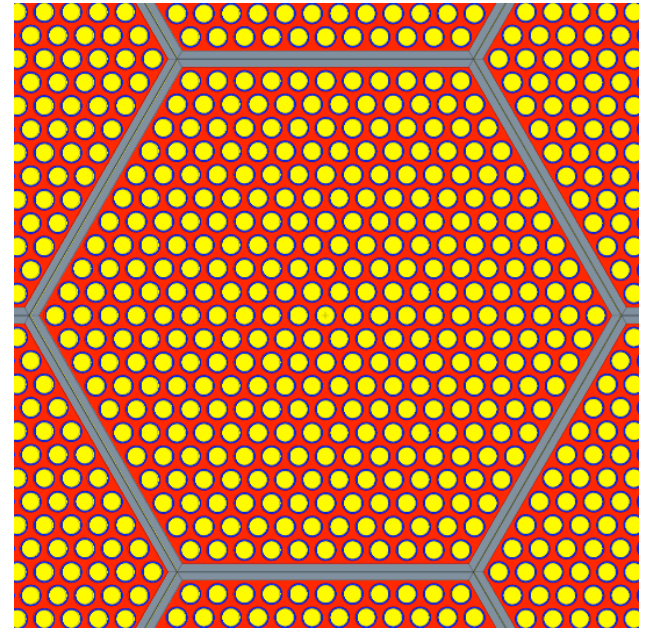

b) ANL-2000 element cross-section.

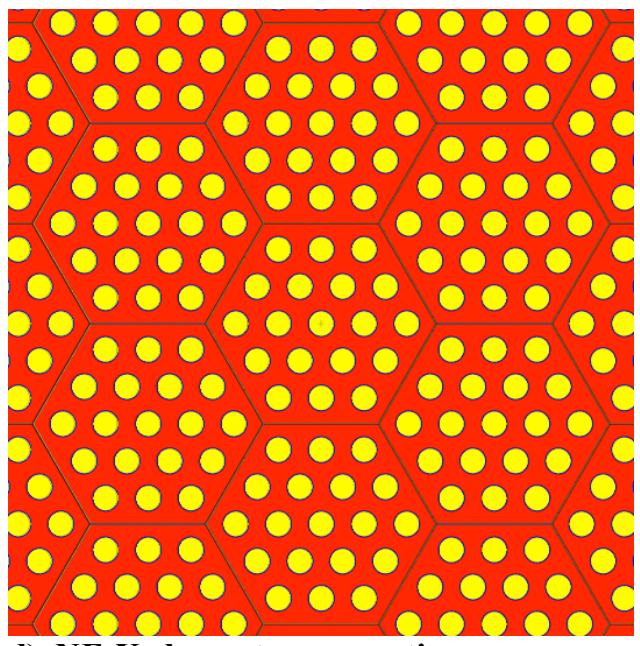

d) NE-X element cross-section.

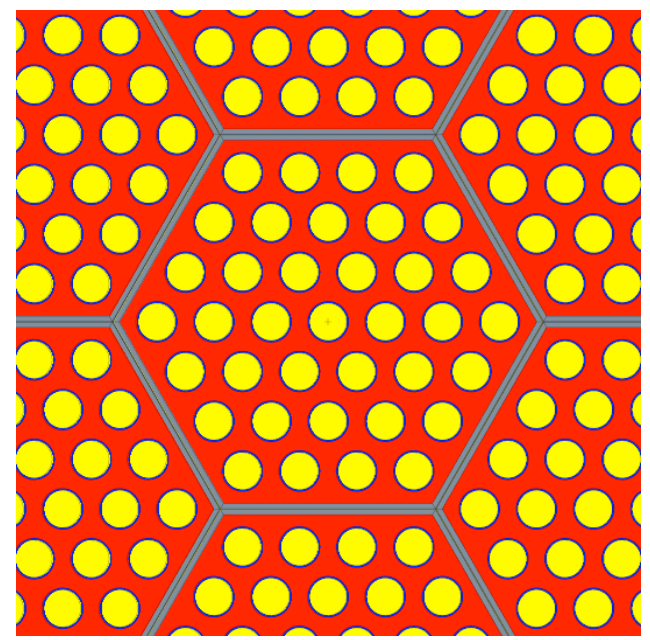

f) XNR-2000-B element cross-section.

Figure 1. Cross-sections of selected hexagonal fuel element types shown in Table 1.

6

American Institute of Aeronautics and Astronautics 


\section{Initial Fast Spectrum Reactor Configurations}

In addition to the considerable range of fuel compositions and hexagonal fuel element types described in the previous section, a large number of different core arrangements have been proposed. Common features include the use of both radial and axial reflectors. Beryllium, beryllium oxide $(\mathrm{BeO})$, and the heavy metals nickel and molybdenum have been evaluated. Beryllium is usually employed for the radial reflector. Axial reflectors are usually included only at the cooler forward end of the reactor core and $\mathrm{BeO}$ is commonly used.

Reactivity control is usually provided by cylindrical control drums located in the radial reflector. The rotating drums contain neutron absorbers over only a portion or sector of the drum. Boron carbide, usually enriched in the

${ }^{10} \mathrm{~B}$ isotope, is the most common absorber material. Hafnium and europium, as $\mathrm{EuO}_{2}$ - $\mathrm{Al}$, are often used in the more thermal spectrum designs but are sometimes also used for the fast spectrum designs. Sometimes moveable reflector sections are employed instead of control drums.

As noted above, past engine designs have incorporated a variety of fuel and clad compositions, fuel element designs, radial and axial reflector configurations, and reactivity control methods. In order to compare fuel element performance on a more consistent basis, a common core layout was adopted for the initial evaluations.

Beryllium at $90 \%$ theoretical density was assumed for the radial reflector. Based on past designs, the reduced density is conservative for reactivity evaluations while allowing $10 \%$ void space to later incorporate cooling channels for thermal management. Three different reflector thicknesses of $10 \mathrm{~cm}, 15 \mathrm{~cm}$, and $20 \mathrm{~cm}$ were considered.

The availability of adequate control swing was estimated using annular zones of absorber material in the reflector to simulate control drums. The relative worths of hafnium, $\mathrm{EuO}_{2}-\mathrm{Al}$, and $\mathrm{B}_{4} \mathrm{C}-\mathrm{Al}$ were compared in several configurations. The performance of hafnium and europium was comparable but inferior to $\mathrm{B}_{4} \mathrm{C}-\mathrm{Al}$. An annular zone at the middle of the reflector was assumed in order to confirm adequate core reactivity with the presence of absorbers in the reflector. Annular zones near the inner and outer radial reflector surfaces were used to estimate available control swing.

\section{Neutronics Results for Criticality Limited Fast Spectrum Reactor Configurations}

Reactor cores made up of the element types shown in Table 1 are being evaluated. A total fuel element length of $78.74 \mathrm{~cm}(31.00 \mathrm{in})$ is assumed for the initial configurations. The active fuel region is $60.96 \mathrm{~cm}(24.00 \mathrm{in})$ with a $2.54 \mathrm{~cm}$ (1.00 in) hydrogen plenum at the hot end and a $15.24 \mathrm{~cm}$ (6.00 in) $\mathrm{BeO}$ axial reflector at the cooler forward end of the core. The geometry of the $\mathrm{BeO}$ axial extension is assumed to be identical with the fuel matrix geometry including number of coolant channels, coolant channel clad thickness and composition, and external clad composition and thickness. The $\mathrm{BeO}$ matrix is assumed to be at $90 \%$ theoretical density.

The fuel composition from the smaller of the two ANL designs is assumed for all evaluations. This composition is, by volume, $60 \% \mathrm{UO}_{2}, 34 \% \mathrm{~W}$, and $6 \% \mathrm{Gd}_{2} \mathrm{O}_{3}$. The fuel matrix is assumed to be at $100 \%$ theoretical density. A constant ${ }^{235} \mathrm{U}$ enrichment of $93 \mathrm{wt} \%$ is assumed. Element exterior clad and borehole clad are assumed to be W-25Re by volume.

Potential core configurations are defined by adjusting both the bounding core radius and the number of fuel elements to fit within that radius while achieving a critical configuration with one or more of the three reflector thicknesses considered. Partial hexagonal elements are used as fillers to complete the cylindrical core geometry. The partial filler elements are assumed to be tungsten at $80 \%$ theoretical density. Based on past designs, the reduced density is conservative for reactivity evaluations while allowing $20 \%$ void space to later incorporate cooling channels for thermal management.

The resulting configurations are simply critical or near critical. The achievable operating powers and resulting thrust levels have not yet been evaluated. The critical configurations are not yet optimized for either lower thrust or higher thrust engines.

Calculated control swing worths shown in the following tables are based on simple but conservative approximate models and must be confirmed by explicitly modeling the control drums. For the reference designs developed during the ANL program, a control swing of 3-5\$ was considered acceptable if a reactivity shimming capability of $\pm 4 \$$ were available.

Both core masses and ${ }^{235} \mathrm{U}$ content for the cores are included in the following tables. Both core mass and ${ }^{235} \mathrm{U}$ content will change as the cores are optimized for either lower thrust or higher thrust engines. 


\section{A. Configurations Based on ANL Heritage Cermet Designs}

Characteristics of selected configurations with cores made up of the two ANL heritage cermet fuel element types are shown in Table 2. Although the dimensions and mass values will change as the configurations are optimized, several trends are apparent. The ANL-200 element from a lower thrust engine design with lower thermal power yields a more compact core with lower core mass and ${ }^{235} \mathrm{U}$ content. The three ANL-200 configurations are adequate from criticality and control swing considerations, but the maximum power density and resulting thrust level have not yet been evaluated. The ANL-2000 element was designed to support operation at a much higher power density. Higher power density forces increased coolant volume fraction and decreased fuel matrix volume fraction in the element and reactor core. The combination yields a significantly larger core with higher core mass and ${ }^{235} \mathrm{U}$ content.

Available control swing appears adequate except for the larger ANL-2000 core with a thin radial reflector. Even if the low value persists when control drums are explicitly modeled, the calculated control swing worth can be raised by small changes to optimize the configuration.

Table 2: Characteristics of selected reactor configurations based on ANL heritage cermet fuel designs.

\begin{tabular}{|c|c|c|c|c|c|c|c|c|}
\hline $\begin{array}{l}\text { Element } \\
\text { Type }\end{array}$ & $\begin{array}{l}\text { Core } \\
\text { Radius } \\
(\mathrm{cm})\end{array}$ & $\begin{array}{l}\text { Number } \\
\text { Of Hex } \\
\text { Elements }\end{array}$ & $\begin{array}{c}\text { Radial } \\
\text { Reflector } \\
\text { Thickness } \\
(\mathrm{cm} \\
\end{array}$ & $\begin{array}{l}\text { Reflector } \\
\text { Outer } \\
\text { Radius } \\
(\mathrm{cm})\end{array}$ & $\begin{array}{l}\text { Calculated } \\
\text { k-effective }\end{array}$ & $\begin{array}{l}\text { Control } \\
\text { Worth } \\
(\$)\end{array}$ & $\begin{array}{l}\text { Core } \\
\text { Mass } \\
(\mathrm{kg}) \\
\end{array}$ & $\begin{array}{c}{ }^{235} \mathrm{U} \\
\text { Mass } \\
(\mathrm{kg})\end{array}$ \\
\hline \multicolumn{9}{|c|}{ 1.092-Inch (2.7737-cm) Exterior Flat-to-Flat Hexagonal Element with 61 Channels } \\
\hline ANL-200 & 17.5 & 121 & 10.0 & 27.5 & 0.9973 & 5.02 & 1000 & 177.3 \\
\hline ANL-200 & 17.5 & 121 & 15.0 & 32.5 & 1.0123 & 6.47 & 1124 & 177.3 \\
\hline ANL-200 & 17.5 & 121 & 20.0 & 37.5 & 1.0195 & 6.89 & 1268 & 177.3 \\
\hline \multicolumn{9}{|c|}{ 1.930-Inch $(4.9022-\mathrm{cm})$ Exterior Flat-to-Flat Hexagonal Element with 331 Channels } \\
\hline ANL-2000 & 37.3 & 187 & 10.0 & 47.3 & 0.9993 & 2.51 & 3738 & 523.7 \\
\hline ANL-2000 & 37.3 & 187 & 15.0 & 52.3 & 1.0069 & 3.44 & 3946 & 523.7 \\
\hline ANL-2000 & 37.3 & 187 & 20.0 & 57.3 & 1.0108 & 3.69 & 4174 & 523.7 \\
\hline
\end{tabular}

\section{B. Configurations Based on the GE-710 Heritage Cermet Design}

Characteristics of selected configurations with cores made up of the GE-710 heritage cermet fuel element type are listed in Table 3. The GE-710 element has a fuel matrix volume fraction similar to the ANL-200 element. The number of fuel elements needed for a critical configuration is different because of different element sizes. The resulting core radius, core mass, and ${ }^{235} \mathrm{U}$ content are comparable. The configurations are adequate from criticality and control swing considerations, but maximum power density and resulting thrust level have not been evaluated.

Table 3: Characteristics of selected reactor configurations based on the GE-710 heritage cermet fuel design.

\begin{tabular}{|c|c|c|c|c|c|c|c|c|}
\hline $\begin{array}{l}\text { Element } \\
\text { Type }\end{array}$ & $\begin{array}{c}\text { Core } \\
\text { Radius } \\
(\mathrm{cm})\end{array}$ & $\begin{array}{l}\text { Number } \\
\text { Of Hex } \\
\text { Elements }\end{array}$ & $\begin{array}{c}\text { Radial } \\
\text { Reflector } \\
\text { Thickness } \\
\text { (cm }\end{array}$ & $\begin{array}{l}\text { Reflector } \\
\text { Outer } \\
\text { Radius } \\
(\mathrm{cm})\end{array}$ & $\begin{array}{l}\text { Calculated } \\
\text { k-effective }\end{array}$ & $\begin{array}{c}\text { Control } \\
\text { Worth } \\
(\$)\end{array}$ & $\begin{array}{l}\text { Core } \\
\text { Mass } \\
(\mathrm{kg})\end{array}$ & $\begin{array}{c}{ }^{235} \mathrm{U} \\
\text { Mass } \\
(\mathrm{kg}) \\
\end{array}$ \\
\hline \multicolumn{9}{|c|}{ 0.9276-Inch (2.3561-cm) Exterior Flat-to-Flat Hexagonal Element with 91 Channels } \\
\hline GE-710 & 18.0 & 169 & 10.0 & 28.0 & 0.9933 & 3.56 & 1171 & 180.5 \\
\hline GE-710 & 18.0 & 169 & 15.0 & 33.0 & 1.0032 & 4.44 & 1297 & 180.5 \\
\hline GE-710 & 18.0 & 169 & 20.0 & 38.0 & 1.0079 & 4.68 & 1444 & 180.5 \\
\hline
\end{tabular}




\section{Configurations Based on Pratt and Whitney Proposed Cermet Fuel Element Designs}

Characteristics of selected configurations with cores made up of the Pratt and Whitney proposed cermet fuel element types are listed in Table 4. Both of the 1.40-inch element types were proposed for a nominal $25,000-\mathrm{lb}_{\mathrm{f}}$ engine design. The 37-channel XNR-2000-B element has a higher fuel matrix volume fraction and yields a smaller configuration than the XNR-2000-A 169-channel element. Interior web thicknesses are 0.022 -in for the XNR-2000-A and 0.061 -in for the XNR-2000-B. The third element type is from a recently proposed design by Pratt \& Whitney Rocketdyne for direct nuclear thermal propulsion. This still proprietary element design was proposed to provide a logical growth path to the bimodal ESCORT and trimodal TRITON designs. The cross-section of the ESCORT element is shown in Figure 2. With one exception, the configurations are adequate from criticality and control swing considerations. Maximum power densities and resulting thrust levels have not yet been evaluated.

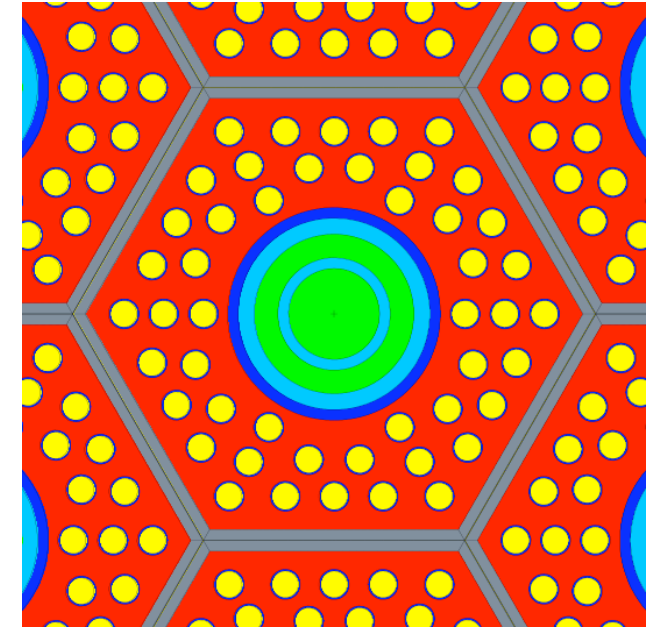

Figure 2. ESCORT element cross-section.

Table 4: Characteristics of selected reactor configurations based on proposed Pratt and Whitney cermet fuel element designs.

\begin{tabular}{|c|c|c|c|c|c|c|c|c|}
\hline $\begin{array}{l}\text { Element } \\
\text { Type }\end{array}$ & $\begin{array}{l}\text { Core } \\
\text { Radius } \\
(\mathrm{cm})\end{array}$ & $\begin{array}{l}\text { Number } \\
\text { Of Hex } \\
\text { Elements }\end{array}$ & $\begin{array}{c}\text { Radial } \\
\text { Reflector } \\
\text { Thickness } \\
(\mathrm{cm}) \\
\end{array}$ & $\begin{array}{l}\text { Reflector } \\
\text { Outer } \\
\text { Radius } \\
(\mathrm{cm}) \\
\end{array}$ & $\begin{array}{l}\text { Calculated } \\
\text { k-effective }\end{array}$ & $\begin{array}{l}\text { Control } \\
\text { Worth } \\
(\$)\end{array}$ & $\begin{array}{l}\text { Core } \\
\text { Mass } \\
(\mathrm{kg}) \\
\end{array}$ & $\begin{array}{l}{ }^{235} \mathrm{U} \\
\text { Mass } \\
(\mathrm{kg})\end{array}$ \\
\hline \multicolumn{9}{|c|}{ 1.40-Inch (3.5560-cm) Exterior Flat-to-Flat Hexagonal Element with 169 Channels } \\
\hline XNR-2000-A & 32.0 & 253 & 10.0 & 42.0 & 0.9915 & 3.05 & 2882 & 403.0 \\
\hline XNR-2000-A & 32.0 & 253 & 15.0 & 47.0 & 1.0004 & 4.10 & 3067 & 403.0 \\
\hline XNR-2000-A & 32.0 & 253 & 20.0 & 52.0 & 1.0048 & 4.35 & 3274 & 403.0 \\
\hline \multicolumn{9}{|c|}{ 1.40-Inch (3.5560-cm) Exterior Flat-to-Flat Hexagonal Element with 37 Channels } \\
\hline XNR-2000-B & 24.0 & 139 & 10.0 & 34.0 & 1.0109 & 3.52 & 1604 & 268.6 \\
\hline XNR-2000-B & 24.0 & 139 & 15.0 & 39.0 & 1.0212 & 4.46 & 1755 & 268.6 \\
\hline XNR-2000-B & 24.0 & 139 & 20.0 & 44.0 & 1.0260 & 4.68 & 1926 & 268.6 \\
\hline \multicolumn{9}{|c|}{ Proprietary Element Design Providing Growth Path to Bimodal and Trimodal Designs (P\&WR) } \\
\hline P\&WR & 20.0 & 61 & 10.0 & 30.0 & 1.0059 & 3.26 & 1296 & 204.5 \\
\hline P\&WR & 20.0 & 61 & 15.0 & 35.0 & 1.0150 & 4.01 & 1430 & 204.5 \\
\hline P\&WR & 20.0 & 61 & 20.0 & 40.0 & 1.0190 & 4.25 & 1585 & 204.5 \\
\hline \multicolumn{9}{|c|}{ 1.70-Inch Exterior Flat-to-Flat Hexagonal Element with 48 Channels } \\
\hline ESCORT & 25.5 & 109 & 10.0 & 35.5 & 1.0066 & 2.66 & 1919 & 295.5 \\
\hline ESCORT & 25.5 & 109 & 15.0 & 40.5 & 1.0142 & 3.36 & 2076 & 295.5 \\
\hline ESCORT & 25.5 & 109 & 20.0 & 45.5 & 1.0178 & 3.56 & 2253 & 295.5 \\
\hline
\end{tabular}




\section{Configurations Using Cermet Fueled Elements Duplicating the NERVA Hexagonal Element Geometry}

Recent consideration has been given to fabrication of a cermet fueled element similar in geometry to the NERVA hexagonal element. Specific element geometry details for the proposed fabrication are not available. The heritage NERVA geometry was assumed here with cermet fuel substituted for composite fuel and W-25Re clad substituted for $\mathrm{ZrC}$ clad. Clad for cermet and graphite elements served different purposes and simple material substitution is not appropriate for design but was considered adequate for this comparison. Characteristics of selected configurations are shown in Table 5.

The similar fuel matrix web thicknesses of 0.060-in for the NE-X element and 0.061-in for the XNR-2000-B element invite comparison. Although the web thicknesses are similar, there are significant differences in the number of coolant / propellant channels (19 for NE-X and 37 for XNR-2000-B) and in the channel diameters (0.101 inch for NE-X and 0.154 inch for XNR-2000-B). Assuming the same fuel matrix power density is achievable in both element types, the combination of fuel matrix volume fraction (about $25 \%$ higher for NE-X) and fuel matrix volume per element (a factor of $\sim 2.77$ higher for XNR-2000-B) will constrain the NE-X element to a lower operating power.

The configurations evaluated are adequate from criticality and control swing considerations and are attractive based on core mass and ${ }^{235} \mathrm{U}$ content. Maximum power density and resulting thrust level have not yet been evaluated.

Table 5: Configurations using cermet fueled elements duplicating the NERVA hexagonal element geometry.

\begin{tabular}{|c|c|c|c|c|c|c|c|c|}
\hline $\begin{array}{l}\text { Element } \\
\text { Type }\end{array}$ & $\begin{array}{l}\text { Core } \\
\text { Radius } \\
(\mathrm{cm})\end{array}$ & $\begin{array}{l}\text { Number } \\
\text { Of Hex } \\
\text { Elements }\end{array}$ & $\begin{array}{c}\text { Radial } \\
\text { Reflector } \\
\text { Thickness } \\
(\mathrm{cm} \\
\end{array}$ & $\begin{array}{l}\text { Reflector } \\
\text { Outer } \\
\text { Radius } \\
(\mathrm{cm})\end{array}$ & $\begin{array}{l}\text { Calculated } \\
\text { k-effective }\end{array}$ & $\begin{array}{c}\text { Control } \\
\text { Worth } \\
(\$)\end{array}$ & $\begin{array}{l}\text { Core } \\
\text { Mass } \\
(\mathrm{kg})\end{array}$ & $\begin{array}{l}{ }^{235} \mathrm{U} \\
\text { Mass } \\
(\mathrm{kg}) \\
\end{array}$ \\
\hline \multicolumn{9}{|c|}{ 0.75-Inch $(1.9050-\mathrm{cm})$ Exterior Flat-to-Flat Hexagonal Element with 19 Channels } \\
\hline NE-X & 17.0 & 256 & 10.0 & 27.0 & 1.0082 & 6.63 & 857 & 178.7 \\
\hline NE-X & 17.0 & 256 & 15.0 & 32.0 & 1.0292 & 8.80 & 979 & 178.7 \\
\hline NE-X & 17.0 & 256 & 20.0 & 37.0 & 1.0397 & 9.46 & 1121 & 178.7 \\
\hline
\end{tabular}

\section{Estimates of System Level Performance for Criticality Limited Fast Spectrum Configurations}

Results reported in the previous sections are from the initial set of neutronic performance evaluations. Configurations are critical and appear to have adequate control swing. Integrated thermal-fluid-structural analyses of the fuel elements are critical to confirming or establishing allowable fuel matrix power densities and ultimately engine system performances. Fuel element and system level performance are being evaluated by NASA Glenn Research Center. Fuel element evaluations and system level performance evaluations are reported in companion papers for the designs based on the ANL-200 element.

Preliminary estimates of allowable core thermal power can be made based on power density considerations and preliminary estimates of engine thrust level can be made by simple thermal power scaling from heritage designs. Results of these preliminary estimates are shown in Table 6.

Four of the eight criticality-limited configurations shown in Table 6 may be categorized as smaller and lower thrust systems. Two of the lower power density designs, those based on the ANL-200 and the NE-X, provide comparable thrust levels of $\sim 39.6 \mathrm{kN}\left(\sim 8,900 \mathrm{lb}_{\mathrm{f}}\right)$. The sizes of both designs are criticality limited in their current configuration. Core modifications may yield smaller critical designs that would provide lower thrust levels while maintaining the same fuel matrix power densities.

Two of the intermediate power density designs, those based on the GE-710 and XNR-2000-B fuel elements, provide comparable thrust levels slightly below the $111.2 \mathrm{kN}\left(25,000-\mathrm{lb}_{\mathrm{f}}\right)$ class. Minor core modifications can bring either design to the $25,000-\mathrm{lb}_{\mathrm{f}}$ thrust level. Engine masses and ${ }^{235} \mathrm{U}$ contents are lower with the GE-710 design but the fuel matrix power density is higher. 
Table 6: Preliminary estimates of system level performance for criticality limited fast spectrum configurations.

\begin{tabular}{|c|c|c|c|c|c|c|}
\hline $\begin{array}{c}\text { Element } \\
\text { Type }\end{array}$ & $\begin{array}{c}\text { Core } \\
\text { Radius } \\
(\mathrm{cm})\end{array}$ & $\begin{array}{l}\text { Active } \\
\text { Fuel } \\
\text { Length } \\
\text { (cm) }\end{array}$ & $\begin{array}{l}\text { Number } \\
\text { Of Hex } \\
\text { Elements }\end{array}$ & $\begin{array}{l}\text { Heritage or Proposed } \\
\text { Design Power Density } \\
\text { In Fuel Matrix } \\
\text { (MW/liter) }\end{array}$ & $\begin{array}{l}\text { Projected } \\
\text { Core } \\
\text { Power } \\
\text { (MWth) }\end{array}$ & $\begin{array}{c}\text { Projected } \\
\text { Approximate } \\
\text { Engine Thrust } \\
\quad(\mathrm{kN})\end{array}$ \\
\hline \multicolumn{7}{|c|}{ Heritage Cermet (ANL) } \\
\hline ANL-200 & 17.5 & 60.96 & 121 & 5.40 & 178 & 39.6 \\
\hline ANL-2000 & 37.3 & 60.96 & 187 & 16.5 & 1610 & 357.0 \\
\hline \multicolumn{7}{|c|}{ Heritage Cermet (GE-710) } \\
\hline GE-710 & 18.0 & 60.96 & 169 & 13.5 & 453 & 100.7 \\
\hline \multicolumn{7}{|c|}{ Pratt \& Whitney Cermet } \\
\hline XNR-2000-A & 32.0 & 60.96 & 253 & 11.4 & 853 & 189.8 \\
\hline XNR-2000-B & 24.0 & 60.96 & 139 & 9.41 & 469 & 104.4 \\
\hline Proprietary & 20.0 & 60.96 & 61 & 5.41 & 206 & 45.7 \\
\hline ESCORT & 25.5 & 60.96 & 109 & 3.52 & 193 & 43.0 \\
\hline \multicolumn{7}{|c|}{ Heritage NERVA Geometry } \\
\hline NE-X & 17.0 & 60.96 & 256 & $5.40 *$ & 179 & 39.9 \\
\hline
\end{tabular}

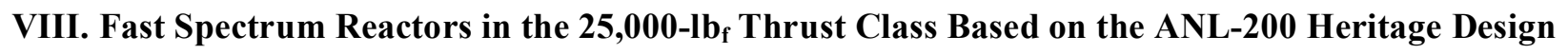

As described earlier, the primary motivation for current interest in $25,000-\mathrm{lb}_{\mathrm{f}}$ class systems is the DRA 5.0 study use of a common nuclear thermal propulsion stage with three $25,000-\mathrm{lb}_{\mathrm{f}}$ engines for all primary mission maneuvers. Options to extend the lower thrust designs into the $25,000-\mathrm{lb}_{\mathrm{f}}$ thrust range include changes in the number of fuel elements and changes in the active fuel length. The method used is to consider combinations of active fuel length and number of fuel elements that can provide the required thermal energy without exceeding the fuel matrix power density in the heritage (or proposed) engine designs.

Characteristics of selected configurations with cores made up using the fuel element from the heritage ANL-200 design are shown in Table 7. The first set is a simple radial growth version containing 349 fuel elements while retaining the $60.96-\mathrm{cm}(24.00$-in) active fuel length. Credit for considerable excess reactivity is taken by reducing the ${ }^{235} \mathrm{U}$ enrichment to $60 \mathrm{wt} \%$. Calculated control swing for the $28.5-\mathrm{cm}$ radius core with a thin radial reflector is marginal at $\sim 2.7 \$$. Even if the low value persists when control drums are explicitly modeled, small changes to optimize the configuration can be expected to raise the calculated control swing worth.

For the second set the active fuel length is increased to $86.36 \mathrm{~cm}$ (34.00 in). The core radius is reduced to 24.0 $\mathrm{cm}$ and contains 241 fuel elements. The ${ }^{235} \mathrm{U}$ enrichment is $70 \mathrm{wt} \%$. Core masses are comparable to the first set and control swings are improved, but the ${ }^{235} \mathrm{U}$ content is higher.

The active fuel length is increased to $121.92 \mathrm{~cm}$ (48.00 in) for the third set. The core radius is reduced to 21.0 $\mathrm{cm}$ and contains 169 fuel elements. As with the second set, the ${ }^{235} \mathrm{U}$ enrichment is $70 \mathrm{wt} \%$. Core masses are increased compared to the second set and ${ }^{235} \mathrm{U}$ masses are comparable.

The ${ }^{235} \mathrm{U}$ masses are high for all configurations. None of the configurations are optimized. Future efforts will likely be focused around the shorter configurations in the first set. These efforts will be deferred pending conclusions from the NASA Glenn thermal and systems level evaluations in progress. 
Table 7: Characteristics of selected reactor configurations based on the ANL-200 heritage cermet fuel design.

\begin{tabular}{|c|c|c|c|c|c|c|c|c|}
\hline $\begin{array}{l}\text { Active } \\
\text { Core } \\
\text { Length } \\
(\mathrm{cm})\end{array}$ & $\begin{array}{c}\text { Core } \\
\text { Radius } \\
(\mathrm{cm})\end{array}$ & $\begin{array}{c}\text { Number } \\
\text { Of Hex } \\
\text { Elements }\end{array}$ & $\begin{array}{c}\text { Radial } \\
\text { Reflector } \\
\text { Thickness } \\
\text { (cm }\end{array}$ & $\begin{array}{l}\text { Reflector } \\
\text { Outer } \\
\text { Radius } \\
(\mathrm{cm})\end{array}$ & $\begin{array}{l}\text { Calculated } \\
\text { k-effective }\end{array}$ & $\begin{array}{c}\text { Control } \\
\text { Worth } \\
(\$)\end{array}$ & $\begin{array}{l}\text { Core } \\
\text { Mass } \\
(\mathrm{kg})\end{array}$ & $\begin{array}{c}{ }^{235} \mathrm{U} \\
\text { Mass } \\
(\mathrm{kg})\end{array}$ \\
\hline \multicolumn{9}{|c|}{ 1.092-Inch $(2.7737-\mathrm{cm})$ Exterior Flat-to-Flat Hexagonal Element with 61 Channels $(60 \mathrm{wt} \%$ U-235) } \\
\hline 60.96 & 28.5 & 349 & 10.0 & 38.5 & 1.0012 & 2.66 & 2351 & 330.1 \\
\hline 60.96 & 28.5 & 349 & 15.0 & 43.5 & 1.0088 & 3.49 & 2520 & 330.1 \\
\hline 60.96 & 28.5 & 349 & 20.0 & 48.5 & 1.0127 & 3.70 & 2710 & 330.1 \\
\hline \multicolumn{9}{|c|}{ 1.092-Inch (2.7737-cm) Exterior Flat-to-Flat Hexagonal Element with 61 Channels $(70 \mathrm{wt} \%$ U-235 } \\
\hline 86.36 & 24.0 & 241 & 10.0 & 34.0 & 1.0099 & 3.41 & 2356 & 376.7 \\
\hline 86.36 & 24.0 & 241 & 15.0 & 39.0 & 1.0199 & 4.42 & 2556 & 376.7 \\
\hline 86.36 & 24.0 & 241 & 20.0 & 44.0 & 1.0250 & 4.71 & 2782 & 376.7 \\
\hline \multicolumn{9}{|c|}{ 1.092-Inch $(2.7737-\mathrm{cm})$ Exterior Flat-to-Flat Hexagonal Element with 61 Channels $(70 \mathrm{wt} \%$ U-235 } \\
\hline 121.92 & 21.0 & 169 & 10.0 & 31.0 & 0.9922 & 3.86 & 2606 & 372.9 \\
\hline 121.92 & 21.0 & 169 & 15.0 & 36.0 & 1.0031 & 4.86 & 2851 & 372.9 \\
\hline 121.92 & 21.0 & 169 & 20.0 & 41.0 & 1.0082 & 5.13 & 3133 & 372.9 \\
\hline
\end{tabular}

Results reported in Table 7 are from the initial set of performance evaluations. Configurations are critical and, with one exception, appear to have adequate control swing. As with the criticality-limited configurations, fuel element and system level performance are being evaluated by NASA Glenn Research Center. Preliminary estimates of allowable core thermal power can be made based on power density considerations and preliminary estimates of engine thrust level can be made by simple thermal power scaling from heritage designs. Results of these preliminary estimates are shown in Table 8 .

Table 8: Preliminary estimates of system level performance for 25,000-lbf class configurations.

\begin{tabular}{|c|c|c|c|c|c|c|c|c|c|}
\hline $\begin{array}{l}\text { Active } \\
\text { Core } \\
\text { Length } \\
(\mathrm{cm})\end{array}$ & $\begin{array}{l}\text { Core } \\
\text { Radius } \\
(\mathrm{cm})\end{array}$ & $\begin{array}{l}\text { Reflector } \\
\text { Outer } \\
\text { Radius } \\
(\mathrm{cm})\end{array}$ & $\begin{array}{l}\text { Number } \\
\text { Of Hex } \\
\text { Elements }\end{array}$ & $\begin{array}{l}\text { Fuel } \\
\text { Wt \% } \\
{ }^{235} \mathrm{U}\end{array}$ & $\begin{array}{l}\text { Core } \\
\text { Mass } \\
(\mathrm{kg})\end{array}$ & $\begin{array}{l}{ }^{235} \mathrm{U} \\
\text { Mass } \\
(\mathrm{kg})\end{array}$ & $\begin{array}{c}\text { Fuel } \\
\text { Matrix } \\
\text { Power } \\
\text { Density } \\
\text { (MW/liter) }\end{array}$ & $\begin{array}{c}\text { Core } \\
\text { Power } \\
(\mathrm{MW})\end{array}$ & $\begin{array}{c}\text { Engine } \\
\text { Thrust } \\
(\mathrm{kN})\end{array}$ \\
\hline \multicolumn{10}{|c|}{ 1.092-Inch (2.7737-cm) Exterior Flat-to-Flat Hexagonal Element with 61 Channels (ANL-200) } \\
\hline 60.96 & 17.5 & 27.5 & 121 & 93 & 1000 & 177.3 & 5.40 & 178 & 39.6 \\
\hline 60.96 & 28.5 & 43.5 & 349 & 60 & 2520 & 330.1 & 5.40 & 513 & 114.1 \\
\hline 86.36 & 24.0 & 34.0 & 241 & 70 & 2356 & 376.7 & 5.40 & 502 & 111.6 \\
\hline 121.92 & 21.0 & 31.0 & 169 & 70 & 2606 & 372.9 & 5.40 & 497 & 110.5 \\
\hline
\end{tabular}




\section{Conclusions and Continuing Work}

Neutronics evaluations have been completed for several fast neutron spectrum reactor configurations suitable for direct nuclear thermal propulsion. Eight different hexagonal fuel element types containing refractory metal alloy (cermet) fuel were evaluated. Small criticality-limited configurations meeting the fundamental neutronic performance requirements of criticality and adequate control swing were developed for each of the eight element types. System level performances have been estimated and more detailed thermal and system level evaluations are being performed at NASA Glenn. These small designs were developed with the goal of utilizing the same fuel elements in growth versions meeting the performance baselined in the DRA 5.0 architecture study. Neutronic and system level performance estimates have been completed for three growth versions using the ANL-200 fuel element design. Evaluations are in progress for growth engine versions using the other fuel element designs.

\section{Acknowledgments}

The authors express their thanks to Chris Moore and John Warren at NASA Headquarters who supported this work through the Nuclear Cryogenic Propulsion Project established as part of the Advanced Exploration Systems Program. Funding was also provided by NASA Glenn Research Center and the Department of Energy's Idaho National Laboratory.

\section{References}

${ }^{1}$ Human Exploration of Mars Design Reference Architecture, SP-2009-566, NASA, July 2009.

${ }^{2}$ National Space Policy of the United States, 28 June 2010.

${ }^{3}$ Daniel R. Koenig, "Experience Gained from the Space Nuclear Rocket Program (Rover)", Los Alamos National Laboratory, Report LA-10062-H, Los Alamos, NM, May 1986.

${ }^{4} 710$ High-Temperature Gas Reactor Program Summary Report, General Electric, Report GEMP-600 Volume 1, Cincinnati, $\mathrm{OH}, 1968$.

${ }^{5}$ Nuclear Rocket Program Terminal Report, Argonne National Laboratory, Report ANL-7236, Argonne, IL, 1968.

${ }^{6} \mathrm{~S}$. K. Bhattacharyya, "An Assessment of Fuels for Nuclear Thermal Propulsion", Argonne National Laboratory, Report ANL/TD/TM01-22, Argonne, IL, December 2001.

${ }^{7}$ F. P. Durham, "Nuclear Engine Definition Study Preliminary Report, Volume 1 - Engine Description", Los Alamos National Laboratory, Report LA-5044-MS Vol 1, Los Alamos, NM, Sept 1972

${ }^{8}$ F. P. Durham, "Nuclear Engine Definition Study Preliminary Report, Volume 2 - Supporting Studies", Los Alamos National Laboratory, Report LA-5044-MS Vol 2, Los Alamos, NM, Sept 1972.

${ }^{9}$ Bruce G. Schnitzler and Stanley K. Borowski, "25,000-lb $\mathrm{f}_{\mathrm{f}}$ Thrust Engine Options Based on the Small Nuclear Rocket Engine Design", AIAA-2009-5239, August 2009.

${ }^{10}$ Bruce G. Schnitzler, Stanley K. Borowski, and James E. Fittje, "Lower Thurst Engine Options Based on the Small Nuclear Roclet Engine Design”, AIAA-2011-5846, August 2011.

${ }^{11}$ X-5 Monte Carlo Team, "MCNP - A General Monte Carlo N-Particle Transport Code, Version 5", Los Alamos National Laboratory, Report LA-UR-03-1987, Los Alamos, NM, April 2003.

${ }^{12}$ D. Garber, (Editor), "Evaluated Nuclear Data File (ENDF/B-V)", National Nuclear Data Center, Brookhaven National Laboratory Report BNL-17541, October 1975.

${ }^{13}$ V. McLane, C. L. Dunford, and P. F. Rose, (Editors), "ENDF-102, Data Formats and Procedures for the Evaluated Nuclear Data File ENDF-6 (Revised)", Brookhaven National Laboratory Report BNL-NCS-44945, November 1995.

${ }^{14}$ R. J. Howerton, et al., "The LLL Evaluated Nuclear Data Library (ENDL): Evaluation Techniques, Reaction Index, and Descriptions of Individual Reactions", Lawrence Livermore National Laboratory Report UCRL-50400, Volume 15, Part A, September 1975

${ }^{15}$ L. W. Carlson, et al., "CERMET Fueled Reactors for Direct Nuclear Thermal Propulsion", AL-TR-89-007, Argonne National Laboratory, Argonne, IL, July 1989.

${ }^{16}$ R. C. Parsley, "Advanced Propulsion Engine Assessment Based on A CERMET Reactor", NASA Conference Publication 10116, Nuclear Propulsion Technology Interchange Meeting, October 1992.

${ }^{17}$ C. Russell Joyner, "The Synergistic Application of Chemical Rocket Component Technologies to the ESCORT Nuclear Bimodal System", AIAA-2000-3211, July 2000.

${ }^{18}$ C. Russell Joyner, et al., "TRITON: A TRImodal Thrust Optimized Nuclear Propulsion and Power System for Advanced Space Missions", AIAA-2004-3863, July 2004.

${ }^{19}$ C. Haertling and R. J. Hanrahan Jr., "Literature review of thermal and radiation performance parameters for hightemperature, uranium dioxide fueled cermet materials", Journal of Nuclear Materials Volume 366, pages 317 - 355, 2007. 